\title{
Substrato à base de esterco de coelho na produção de mudas de alface
}

\author{
Claudete Martins da Silva PEREIRA' ${ }^{1}$, Luiz Fernando de Sousa ANTUNES1*, \\ Adriana Maria de $\mathrm{AQUINO}^{2}$, Marco Antonio de Almeida LEAL ${ }^{2}$
}

\author{
${ }^{1}$ Instituto de Agronomia, Universidade Federal Rural do Rio de Janeiro, Seropédica, RJ, Brasil. (ORCID: 0000-0002-2847-5353; *) \\ ${ }^{2}$ Embrapa Agrobiologia, Seropédica, RJ, Brasil. (ORCID: 0000-0003-3718-4512; 0000-0003-3988-2277) \\ *E-mail: fernando.ufrri.agro@gmail.com (ORCID: 0000-0001-8315-4213)
}

\begin{abstract}
Recebido em: 07/03/2019; Aceito em: 15/10/2019; Publicado em: 04/02/2020.
RESUMO: O uso de esterco de coelho pode contribuir para suprir a crescente demanda por substratos destinados à produção de mudas de hortaliças. Objetivou-se com este trabalho avaliar a utilização de esterco de coelho como substrato para produção de mudas de alface, após ser submetido a três diferentes processos de estabilização: vermicompostagem, processamento por meio de larvas de Cetoniinae e compostagem natural. Inicialmente foi realizada uma minuciosa caracterização dos substratos avaliados, determinando-se os teores totais, os teores disponíveis e a proporção da fração disponível de N, Ca, Mg, P e K, a densidade e a porosidade. Também foram avaliadas as variações do $\mathrm{pH}$ e da condutividade elétrica dos substratos ao longo de 28 dias do desenvolvimento das mudas. O desempenho dos diferentes substratos na produção de mudas de alface foi avaliado por meio da emergência das sementes e de características das mudas relacionadas com o desenvolvimento da parte aérea e da raiz. Pode-se concluir que o uso de esterco de coelho como substrato para a produção de mudas de alface é uma prática recomendada, desde que o seu processamento seja realizado por meio de vermicompostagem com Eisenia fetida ou por meio de larvas de Cetonïnae.
\end{abstract}

Palavras-chave: Cetonïnae; Eisenia fétida; Lactuca sativa; composto orgânico.

\section{Rabbit manure based substrate for the production of lettuce seedlings}

\begin{abstract}
The use of rabbit manure can contribute to supply the growing the demand by substrates intended for the production of vegetable seedlings, This job was realized with the objective of check the use of rabbit manure as substrate to the production of lettuce seedlings, after being submitted to three different stabilization processes: vermicomposting, processing by means of Cetoniinae larvae and natural composting. Were determined the total levels, available and the proportion of the available fraction of $\mathrm{N}, \mathrm{Ca}, \mathrm{Mg}, \mathrm{P}$ and $\mathrm{K}$, the density and a porosity of the substrates. It was also checked the $\mathrm{pH}$ variations and of the electric conductivity of the substrates over 28 days of the seedlings development. The performance of the different substrates in the production of lettuce seedlings was evaluated through seed emergence and seedling characteristics related to shoot and root development. It can be concluded that the use of rabbit manure as substrate to lettuce seedlings production is a recommended practice, provide that it is processed by means of vermicomposting with Eisenia fetida or by means of larvae of Cetoniinae.
\end{abstract}

Keywords: Cetoniinae; Eisenia fétida; Lactuca sativa; organic compost.

\section{INTRODUÇÃO}

A alface é a hortaliça folhosa mais cultivada no país (IBGE, 2017) e faz parte da dieta da maioria dos brasileiros. Os dados do último Censo Agropecuário revelaram que a produção anual brasileira de alface no período de referência 2016-2017 foi de 908.186 toneladas, das quais 65,19\% foram produzidas na região Sudeste, seguida pelas produções das regiões: Sul com 12,87\%, Centro-Oeste com 10,95\%, Nordeste com 8,21\% e Norte com 2,77\% (IBGE, 2017).

O substrato é imprescindível na produção de mudas de hortaliças e suas propriedades físicas, químicas e biológicas determinarão a qualidade final das mudas a serem transplantadas aos campos de produção, refletindo na uniformidade dos estandes $e$, consequentemente, na produtividade final das culturas (ANTUNES et al., 2019). Uma forma de suprir a demanda por substratos é a utilização de resíduos e subprodutos de composição orgânica que estejam localmente disponíveis.
A cunicultura vem crescendo no Brasil, uma vez que o coelho tem fácil adaptação às condições adversas de clima, manejo e alimentação (BRUM JÚNIOR et al., 2012). Estercos são fertilizantes orgânicos que geralmente apresentam elevados conteúdos de matéria orgânica e concentração moderada de $\mathrm{N}$, sendo que o esterco de coelho apresenta elevada proporção de matéria orgânica e teor mediano de N (MORAL et al., 2005). De acordo com Queiroz et al. (2014), o esterco de coelho pode ser utilizado como fonte de nutrientes para complementar a adubação de milheto.

É comum a utilização de estercos como matéria-prima na formulação de substratos, mas para isso, é necessário que estes materiais estejam estabilizados. $O$ processo de estabilização geralmente ocorre por meio da atuação predominante de microrganismos, mas também pode ocorrer por meio da ação de macrorganismos. Gómez-Brandón et al. (2013) demonstraram que é possível realizar o 
processamento de esterco de coelho em grande escala por meio da vermicompostagem com Eusenia fetida, e Pereira et al. (2017) observou que larvas de Gymnnetis Chalcipes, pertencente à subfamília Cetoniinae, pode colonizar fezes de coelho, exercendo ação copronecrófaga. Outra técnica que se apresenta como alternativa é a compostagem, gerando um produto final estabilizado e sanitizado para uso na agricultura (BERNAL et al., 2009). Entretanto, são escassos trabalhos associando o uso de esterco de coelho processado por diferentes técnicas para sua inserção em substratos para mudas de alface.

Visando suprir a carência de informações sobre a viabilidade técnica da utilização de esterco de coelho na formulação de substrato para a produção de mudas de hortaliças e também sobre a melhor forma de processá-lo, realizou-se este trabalho, que avaliou a utilização de esterco de coelho como substrato para produção de mudas de alface, após ser submetido a três diferentes processos de estabilização.

\section{MATERIAL E MÉTODOS}

\subsection{Processamento do esterco de coelho}

O esterco de coelho foi obtido no setor de Cunicultura da Universidade Federal Rural do Estado do Rio de Janeiro (UFRRJ). Após sua coleta, este material foi submetido a um processo de pré-estabilização durante 30 dias, que consistiu em regas constantes para reduzir os efeitos nocivos de elevada salinidade e de elevadas temperaturas, tornando o material adequado para a sua colonização com minhocas.

Em seguida, o esterco de coelho foi submetido a três formas de processamento, visando a sua estabilização, a saber: 1) por meio de vermicompostagem; 2) por meio da ação de larvas de Cetoniinae e 3) por meio de compostagem natural, sem minhocas e sem larvas. Para cada forma de processamento foram utilizados três recipientes plásticos, tipo floreira, com volume de 5 litros. No processamento por vermicompostagem foram utilizadas em cada recipiente 20 minhocas adultas da espécie Eisenia fetida ("Vermelha-daCalifórnia") indicada por sua alta prolificidade, precocidade, elevada sobrevivência e adaptabilidade às condições de cativeiro (AQUINO, 2005). E no processamento por larvas de Cetoniinae foram utilizadas em cada recipiente 20 larvas do besouro decompositor, coletadas no Setor de Cunicultura da UFRRJ, sendo 10 em estágio L2 e 10 em estágio L3 (PEREIRA, 2017).

Para evitar oviposição de moscas ou a entrada de outros organismos indesejáveis, os recipientes foram cobertos com tela mosquiteira. Foram efetuadas regas com água destilada durante o período de processamento, buscando-se manter a umidade em valores próximos a $60 \%$.

Após 90 dias de incubação, considerou-se que as três formas de processamento utilizadas proporcionaram a estabilização do esterco de coelho, com base em resultados de análises de emissões potenciais de $\mathrm{CO}_{2}$ e de $\mathrm{NH}_{3}$, realizadas conforme metodologia descrita por Oliveira et al. (2014) modificada, alterando-se a temperatura de incubação de $25^{\circ} \mathrm{C}$ para $30^{\circ} \mathrm{C}$.

\subsection{Produção das mudas de alface}

O trabalho foi realizado em casa de vegetação, no Sistema Integrado de Produção Agroecológica (SIPA), conhecido como Fazendinha Agroecológica, localizado em SeropédicaRJ (22 45' S; 43 40’ W; 26 m de altitude). A região apresenta um clima tipo Aw segundo a classificação de Koppen, com verão úmido e inverno seco. A temperatura média anual é de $24,6{ }^{\circ} \mathrm{C}$ e a precipitação média são de $1200 \mathrm{~mm}$, sendo os meses de julho e agosto os mais secos (INMET, 2019). O experimento com mudas foi conduzido em delineamento inteiramente casualizado com quatro repetições e quatro tratamentos, a saber: i) T1- Esterco de coelho processado por vermicompostagem; ii) T2- Esterco de coelho processado por larvas de Cetoniinae; iii) T3- Esterco de coelho processado por compostagem natural; iv) T4- Substrato SIPA.

O substrato SIPA foi utilizado como referência, por ser o substrato padrão para a produção de mudas de hortaliças no SIPA. Ele é constituído por $83 \%$ de húmus de minhoca produzido com esterco bovino $+15 \%$ de fino de carvão + $2 \%$ de torta de mamona.

As mudas foram produzidas em bandejas de poliestireno com 200 células. Utilizou-se alface cultivar "Regiane", das quais foram semeadas duas sementes peletizadas por célula em 6 de julho de 2016. Foi realizado desbaste aos oito dias após a semeadura, mantendo-se uma planta por célula. Devido à reduzida quantidade de substrato disponível, cada parcela foi constituída por 50 células. Para reduzir influências locais, as bandejas foram trocadas de lugar duas vezes por semana.

2.3. Avaliações das características químicas e físicas dos substratos

Coletou-se amostras dos diferentes substratos no momento do preenchimento das bandejas, sendo determinados os teores totais, teores disponíveis e a proporção da fração disponível de N, Ca, Mg, P e K.

Os teores totais de $\mathrm{N}, \mathrm{Ca}, \mathrm{Mg}, \mathrm{K}$ e $\mathrm{P}$ foram avaliados no laboratório da Embrapa Agrobiologia por meio de digestão da amostra (TEIXEIRA et al., 2017). Os teores disponíveis destes nutrientes foram avaliados por meio de extração, sendo que para Ca e Mg utilizou-se solução extratora $\mathrm{KCl}$ 1,0 M, e para K e P utilizou-se solução extratora Mehlich 1 (TEIXEIRA et al., 2017). A extração do $\mathrm{N}$ foi realizada por meio de solução de $\mathrm{KCl}$ 1,0 M, e posteriormente, o extrato obtido foi submetido a digestão com adição de Liga de Devarda, conforme descrito por Liao (1981).

Os teores de nutrientes totais e disponíveis foram obtidos com base na massa seca da amostra, mas como substratos são materiais utilizados com base no volume, e não na massa, os valores foram convertidos para unidade baseada no volume $\left(\mathrm{kg} \mathrm{m}^{-3}\right)$ utilizando-se os valores de densidade aparente. Os teores de nutrientes disponíveis não foram convertidos, pois normalmente são apresentados com base no volume da amostra. A proporção da fração disponível dos nutrientes (em \%) foi calculada dividindo-se o teor disponível pelo teor total de nutrientes, multiplicando-se este resultado por 100 .

A densidade e a porosidade dos substratos foram obtidas pelo método da mesa de tensão, utilizando anéis metálicos de $100 \mathrm{~mL}$ e tensão de $60 \mathrm{~cm}$ (TEIXEIRA et al., 2017).

\subsection{Variações do pH e da condutividade elétrica dos substratos}

As variações do $\mathrm{pH}$ e da condutividade elétrica dos substratos ao longo do desenvolvimento das mudas foram avaliadas por meio de amostragens realizadas aos $0,7,14,21$ e 28 dias após a semeadura. Foram coletados substratos de quatro células, totalizando $50 \mathrm{~mL}$ de substrato para cada parcela. As amostras foram armazenadas em freezer. A 
análise de $\mathrm{pH}$ foi realizada em solução de água destilada (5:1 $\mathrm{v} / \mathrm{v}$ ) e a condutividade elétrica foi determinada no mesmo extrato aquoso (BRASIL, 2007).

A análise estatística foi realizada por meio da aplicação inicial de teste de normalidade, sendo que os dados considerados não normais sofreram transformação de $\log (\mathrm{x})$. Em seguida, foi realizada a análise de variância do esquema parcela subdividida, com substrato na parcela e tempos de desenvolvimento das mudas na sub-parcela, em delineamento inteiramente casualizado com quatro repetições. O comportamento de cada tratamento ao longo do desenvolvimento das mudas foi apresentado por meio de gráficos contendo os valores médios e o erro padrão.

\subsection{Avaliação das mudas de alface}

A porcentagem de emergência foi avaliada aos sete dias após a semeadura. Aos 28 dias após a semeadura, quando as mudas estavam prontas para o transplante, foram avaliadas dez mudas por parcela em relação às seguintes características: altura da parte aérea, número de folhas, produção de massa fresca de parte aérea e de raiz e o volume de raiz. Também foi avaliada a estabilidade do torrão em quatro mudas por parcela.

A altura da muda foi medida pela distância entre o colo da planta e a gema apical, com auxílio de régua milimetrada. Para determinar a massa fresca da parte aérea e a massa fresca de raiz, as mudas foram seccionadas na região do colo da muda, separando a parte aérea da parte radicular. O volume de raiz foi determinado lavando-se o sistema radicular em água corrente, retirando-se qualquer resíduo de substrato eventualmente aderido. Em seguida, a raiz foi inserida em uma proveta de $10 \mathrm{~mL}$ quantificando-se o deslocamento de água.

A estabilidade do torrão foi avaliada por meio da sua coesão. Foram atribuídas notas de 1 a 4, de acordo com a permanência do torrão no recipiente. A nota 1 corresponde aos torrões com pior estabilidade e a nota 4 aqueles de melhor estabilidade, conforme descrito a seguir - Nota 1: Baixa estabilidade, acima de $50 \%$ do torrão fica retido no recipiente, e o torrão não permanece coeso; Nota 2: Entre $10 \%$ e $30 \%$ do torrão fica retido no recipiente, sendo que o torrão não permanece coeso; Nota 3: O torrão se destaca do recipiente, porém não permanece coeso; Nota 4: Todo o torrão é destacado do recipiente e mais de $90 \%$ dele permanece coeso.

A análise estatística foi realizada por meio da aplicação inicial de teste de normalidade, sendo que os dados considerados não normais sofreram transformação por Log (x). Os dados foram submetidos à análise de variância com o auxílio do Software Sisvar (FERREIRA, 2014), e quando o efeito dos tratamentos foi significativo pelo teste $F(p \leq 0,05)$, foi realizado o teste Scott-Knott para agrupamento de médias.

\section{RESULTADOS}

33.1. Caracterização química e física dos substratos

Os teores totais e disponíveis e a proporção da forma disponíveis de $\mathrm{N}, \mathrm{Ca}, \mathrm{Mg}, \mathrm{P}$ e $\mathrm{K}$ dos substratos avaliados estão apresentados na Tabela 1. Observa-se em relação ao N, que geralmente é o nutriente mais demandado pelas mudas, que todos os substratos apresentaram teores totais muito semelhantes, mas os teores disponíveis dos substratos formulados a base de esterco de coelho foram muito superiores ao do substrato SIPA (T4).

Os resultados de densidade volumétrica e de porosidade estão a presentados na Tabela 2. Observa-se que todos os substratos apresentaram valores semelhantes para densidade e porosidade total, sendo que ocorreram maiores diferenças em relação à macroporosidade e à microporosidade.

3.2. Variação do $\mathrm{pH}$ e da condutividade elétrica dos substratos durante o desenvolvimento das mudas de alface

Tanto o pH quanto a condutividade elétrica apresentaram efeitos significativos $(p \leq 0,001)$ dos fatores substrato, tempo de desenvolvimento das mudas e interação entre substrato e tempo de desenvolvimento.

Tabela 1. Teores totais, teores disponíveis e proporção dos teores disponíveis de macronutrientes dos substratos utilizados para produção de mudas de alface. Seropédica-RJ, 2016.

Table 1. Total contents, available contents and proportion of available macronutrient contents of the substrates used to produce lettuce seedlings. Seropédica-RJ, 2016.

\begin{tabular}{|c|c|c|c|c|c|}
\hline \multirow{2}{*}{ Substratos } & $\mathrm{N}$ & $\mathrm{Ca}$ & $\mathrm{Mg}$ & $\mathrm{P}$ & K \\
\hline & \multicolumn{5}{|c|}{ Teores totais $\left(\mathrm{mg} \mathrm{L}^{-1}\right)$} \\
\hline T1 - Esterco de coelho processado por vermicompostagem & 6171 & 9473,8 & 3189,2 & 8022,1 & 3997,7 \\
\hline T2 - Esterco de coelho processado por larvas de Cetoniinae & 8206 & 11622,8 & 4259,0 & 10244,0 & 5826,7 \\
\hline T3 - Esterco de coelho processado por compostagem natural & 6347 & 6928,8 & 2762,8 & 6547,6 & 5009,4 \\
\hline T4 - Substrato SIPA & 7034 & 4620,3 & 2581,2 & 2021,2 & 4354,7 \\
\hline \multirow{2}{*}{ Substratos } & $\mathrm{N}$ & $\mathrm{Ca}$ & $\mathrm{Mg}$ & $\mathrm{P}$ & $\mathrm{K}$ \\
\hline & \multicolumn{5}{|c|}{ Teores disponíveis $\left(\mathrm{mg} \mathrm{L}^{-1}\right)$} \\
\hline T1 - Esterco de coelho processado por vermicompostagem & 468,6 & 998,0 & 1055,8 & 6196,9 & 3472,8 \\
\hline T2 - Esterco de coelho processado por larvas de Cetoniinae & 612,7 & 876,0 & 1244,2 & 6865,5 & 5425,0 \\
\hline T3 - Esterco de coelho processado por compostagem natural & 483,5 & 674,0 & 722,9 & 5487,3 & 4268,2 \\
\hline T4 - Substrato SIPA & 202,5 & 900,0 & 748,4 & 1362,2 & 4224,8 \\
\hline \multirow{2}{*}{ Substratos } & $\mathrm{N}$ & $\mathrm{Ca}$ & $\mathrm{Mg}$ & $\mathrm{P}$ & $\mathrm{K}$ \\
\hline & \multicolumn{5}{|c|}{ Proporção de nutriente disponível (\%) } \\
\hline T1 - Esterco de coelho processado por vermicompostagem & 7,6 & 10,5 & 33,1 & 77,2 & 86,9 \\
\hline T2 - Esterco de coelho processado por larvas de Cetoniinae & 7,5 & 7,5 & 29,2 & 67,0 & 93,1 \\
\hline T3 - Esterco de coelho processado por compostagem natural & 7,6 & 9,7 & 26,2 & 83,8 & 85,2 \\
\hline T4 - Substrato SIPA & 2,9 & 19,5 & 29,0 & 67,4 & 97,0 \\
\hline
\end{tabular}


Tabela 2. Valores de densidade volumétrica, porosidade total, microporosidade e macroporosidade dos substratos utilizados para produção de mudas de alface. Seropédica-RJ, 2016.

Table 2. Volumetric density values, total porosity, microporosity and macroporosity of the substrates used to produce lettuce seedlings. Seropédica-RJ, 2016.

\begin{tabular}{|c|c|c|c|c|}
\hline \multirow{2}{*}{ Substratos } & \multirow{2}{*}{$\begin{array}{c}\text { Densidade } \\
\left(\mathrm{kg} \mathrm{m}^{-3}\right)\end{array}$} & \multicolumn{3}{|c|}{ Porosidade $(\%)$} \\
\hline & & Total & Micro & Macro \\
\hline T1 - Esterco de coelho processado por vermicompostagem & 287,0 & 71,0 & 41,7 & 30,2 \\
\hline T2 - Esterco de coelho processado por larvas de Cetoniinae & 319,3 & 71,2 & 39,9 & 31,3 \\
\hline T3 - Esterco de coelho processado por compostagem natural & 350,0 & 83,0 & 60,6 & 22,4 \\
\hline T4 - Substrato SIPA & 307,2 & 74,0 & 47,9 & 26,1 \\
\hline
\end{tabular}

$\mathrm{O} \mathrm{pH}$ de todos os substratos se manteve com valores entre 7,7 e 8,8 ao longo do desenvolvimento das mudas (Figura 1). Já para a condutividade elétrica, todos os substratos apresentaram grande redução em seus valores nos primeiros sete dias de desenvolvimento das mudas (Figura 2), seguido de uma redução menos intensa até o $28^{\circ}$ dia.

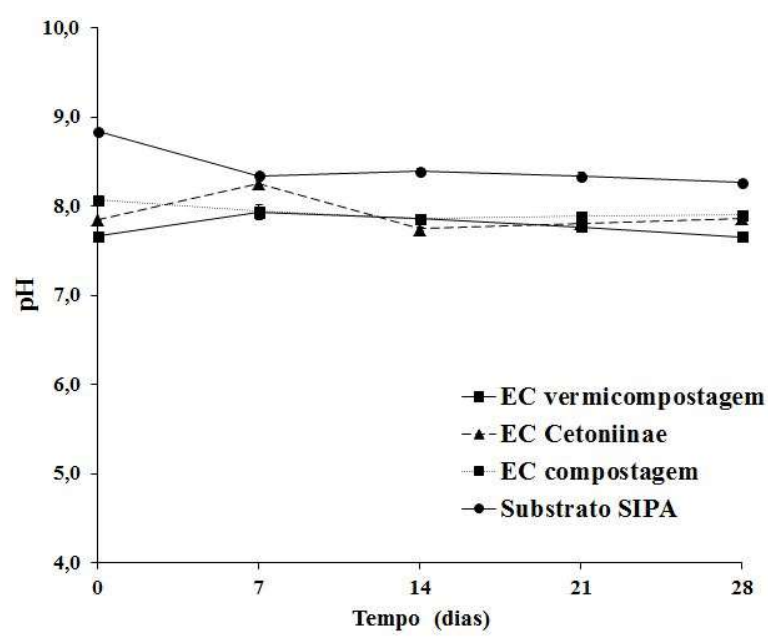

Figura 1. Valores de $\mathrm{pH}$ observados em diferentes substratos durante o desenvolvimento de mudas de alface. Seropédica-RJ, 2016.

Figure 1. Values of $\mathrm{pH}$ observed in different substrates during the development of lettuce seedlings. Seropédica-RJ, 2016.

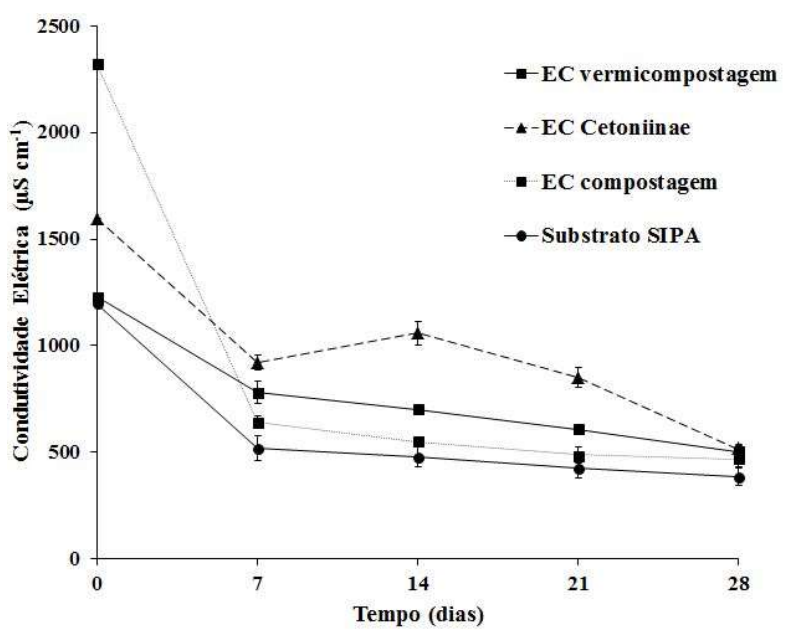

Figura 2. Valores de condutividade elétrica observados em diferentes substratos durante o desenvolvimento de mudas de alface. Seropédica-RJ, 2016.

Figure 2. Values of electrical conductivity observed in different substrates during the development of lettuce seedlings. SeropédicaRJ, 2016
O substrato de esterco de coelho processado por compostagem natural (T3) apresentou elevado valor de condutividade elétrica no tempo zero $\left(2,32 \mathrm{mS} \mathrm{cm}^{-1}\right)$, muito superior ao observado nos demais substratos, que apresentaram valores entre 1,20 e $1,60 \mathrm{mS} \mathrm{cm}^{-1}$. Esse substrato também apresentou acentuada redução dos valores de condutividade elétrica nos primeiros sete dias de desenvolvimento das mudas, enquanto os demais substratos apresentaram menor redução da condutividade elétrica ao longo dos 28 dias de desenvolvimento das mudas, sendo que os substratos de esterco de coelho processados por larvas de Cetoniinae e por vermicompostagem foram os que mantiveram maior condutividade elétrica aos 7, 14 e 21 dias.

3.3. Desenvolvimento das mudas de alface nos diferentes substratos

Os substratos influenciaram a percentagem de emergência de plântulas, sendo que a semeadura em substrato de esterco de coelho processados por meio de compostagem natural (T3) apresentaram menor valor, quando comparado aos demais substratos (Tabela 3).

No que se refere à altura de plantas, número de folhas e massa fresca da parte aérea das mudas, os maiores valores para estes parâmetros foram obtidos nos substratos de esterco de coelho processados por meio da vermicompostagem (T1) e larvas de Cetonïnae (T2), quando comparados ao substrato SIPA (T4) (Tabela 3).

Não houve diferenças significativas entre os substratos em relação à massa fresca de raiz e seus respectivos volumes. Por outro lado, os substratos constituídos por esterco de coelho processado por meio de vermicompostagem (T1) e de larvas de Cetoniinae (T2) proporcionaram maior estabilidade do torrão (Tabela 3).

\section{DISCUSSÃO}

4.1. Caracterização química e física dos substratos

Não existem informações atuais sobre os níveis adequados de nutrientes contidos em substratos para plantas, no entanto, Gonçalves; Poggiani (1996) estabeleceram escalas de valores para a interpretação das características químicas de substratos, tais como os níveis adequados de macronutrientes.

O nitrogênio é o nutriente que influencia na maioria dos processos fisiológicos que ocorrem nas plantas, tais como a síntese proteica e a fotossíntese, sendo o nutriente mais limitante à produção de biomassa (YONG et al., 2010). Observa-se na Tabela 1 que todos os substratos avaliados apresentavam teores semelhantes de $\mathrm{N}$ total, mas grande diferença em relação à fração disponível deste nutriente, com os substratos formulados à base de esterco de coelho apresentando valores entre 468,6 e 612,7 $\mathrm{mg} \mathrm{L}^{-1}$, enquanto o substrato SIPA apresentou apenas $202,5 \mathrm{mg} \mathrm{L}^{-1}$. Como o 
período de desenvolvimento das mudas de alface foi de apenas 28 dias, provavelmente não houve tempo suficiente para que esta diferença de disponibilidade de nitrogênio fosse compensada pela mineralização do nitrogênio presente em formas indisponíveis, o que pode explicar o maior desenvolvimento da parte aérea das mudas produzidas nos substratos com os maiores teores de $\mathrm{N}$ disponíveis.

Tabela 3. Percentuais de emergência (E), altura da planta (AP), número de folhas (NF), massa fresca de parte aérea (MFPA), massa fresca de raiz (MFR), volume radicular (VR) e estabilidade do torrão (ET) de mudas de alface produzidas com diferentes substratos orgânicos. Seropédica-RJ, 2016.

Table 3. Percentage of emergence (E), plant height (AP), number of leaves (NF), fresh shoot mass (MFPA), fresh root mass (MFR), root volume (VR) and clod stability (ET) of lettuce seedlings produced with different organic substrates. Seropédica-RJ, 2016.

\begin{tabular}{|c|c|c|c|c|c|c|c|}
\hline \multirow{2}{*}{ Substratos } & \multirow{2}{*}{$\begin{array}{c}\mathrm{E} \\
(\%)\end{array}$} & \multirow{2}{*}{$\begin{array}{l}\mathrm{AP}^{1} \\
(\mathrm{~cm})\end{array}$} & \multirow{2}{*}{ NF } & MFPA & MFR & \multirow{2}{*}{$\begin{array}{c}\mathrm{VR} \\
(\mathrm{mL})\end{array}$} & \multirow{2}{*}{ ET } \\
\hline & & & & \multicolumn{2}{|c|}{ mg planta $^{-1}$} & & \\
\hline T1 - Esterco de coelho processado p & $99,50 \mathrm{a}$ & $8,32 \mathrm{a}$ & $5,63 \mathrm{a}$ & $1242,8 \mathrm{~b}$ & $300,3 \mathrm{a}$ & $2,62 \mathrm{a}$ & $3,44 \mathrm{a}$ \\
\hline T2 - Esterco de coelho processado por la & $97,50 \mathrm{a}$ & $9,05 \mathrm{a}$ & $5,50 \mathrm{a}$ & $1470,8 \mathrm{a}$ & $295,8 \mathrm{a}$ & $2,66 \mathrm{a}$ & 3,31 a \\
\hline T3 - Esterco de coelho processado por compostagem natural & $69,00 \mathrm{~b}$ & $4,98 \mathrm{c}$ & $4,88 \mathrm{~b}$ & $563,5 \mathrm{~d}$ & $298,0 \mathrm{a}$ & $2,65 \mathrm{a}$ & $2,38 \mathrm{~b}$ \\
\hline T4 - Substrato SIPA & $91,50 \mathrm{a}$ & $6,73 \mathrm{~b}$ & $4,43 \mathrm{~b}$ & $895,5 \mathrm{c}$ & $305,0 \mathrm{a}$ & $2,68 \mathrm{a}$ & $2,13 \mathrm{~b}$ \\
\hline $\mathrm{CV}(\%)$ & 11,83 & 4,80 & 5,26 & 13,16 & 1,78 & 1,58 & 12,96 \\
\hline
\end{tabular}

Médias seguidas por mesma letra na coluna não diferem entre si pelo teste de Tukey Scott-Knott ( $\mathrm{p} \leq$ 0,05). 1- Dados transformados por Log(x).

O fósforo apresenta funções estruturais importantes ao desenvolvimento vegetal, participando da fotossíntese, respiração, divisão e crescimento celular e principalmente, no fornecimento de energia (ATP), o que resulta no maior crescimento e desenvolvimento inicial das plantas, principalmente do sistema radicular (VIEIRA et al., 2015). Os teores de fósforo considerados adequados variam na faixa de 400 a $800 \mathrm{mg} \mathrm{L}^{-1}$ (GONÇALVES; POGGIANI,1996), porém os teores de fósforo disponível (Tabela 1) ficaram muito acima desta faixa para todos os substratos, e por isso, a disponibilidade deste nutriente provavelmente não teve contribuição relevante para as diferentes respostas das mudas de alface aos diferentes substratos.

Para potássio considera-se adequado níveis entre 1173 a $3910 \mathrm{mg} \mathrm{L}^{-1}$ (GONÇALVES; POGGIANI,1996) e todos os substratos registraram valores acima do estabelecido (Tabela 1). Por isso, provavelmente este nutriente também não teve influência relevante sobre as respostas das mudas de alface aos diferentes substratos. Ao contrário do nitrogênio e do fósforo, o potássio não apresenta função estrutural, contudo está associado à maior resistência das plantas quando submetidas a condições adversas, como baixa disponibilidade de água e temperaturas extremas, por conta de sua função na abertura e fechamento dos estômatos (BERTI et al.,2017). No entanto, nenhuma destas condições adversas foram observadas ao longo do desenvolvimento das mudas de alface.

Os níveis de cálcio considerados adequados variam de 2004 a 4008 mg L-1(GONÇALVES; POGGIANI,1996) e neste trabalho todos os substratos apresentaram níveis abaixo do adequado, variando de 674 a $998 \mathrm{mg} \mathrm{L}^{-1}$ de cálcio disponível. O cálcio é um elemento fundamental na permeabilidade das membranas e manutenção da integridade celular, sendo exigido para a divisão e expansão das células. É componente da parede celular e lamela média, e ainda serve como ativador de algumas enzimas envolvidas no metabolismo de carboidratos, como a alfa-amilase (GARRONE et al., 2016). Mas é improvável que a disponibilidade deste elemento tenha alguma influência relevante no desenvolvimento da parte aérea das mudas de alface, pois o substrato T2, que proporcionou a melhor resposta, apresentou teor de cálcio menor que o substrato T4, que proporcionou a pior resposta.
Todos os substratos apresentaram teores de magnésio dentro da faixa considerada adequada, que de acordo com Gonçalves; Poggiani (1996) varia de 607 a $1215 \mathrm{mg} \mathrm{L}^{-1}$, e portanto, provavelmente este nutriente também não teve contribuição relevante para as diferentes respostas das mudas de alface aos diferentes substratos. Dentre as funções do magnésio destaca-se o seu papel na composição da molécula de clorofila, participando de vários processos, como fotossíntese, respiração, síntese de carboidratos e proteínas (SILVA et al., 2017).

As propriedades físicas de um substrato são consideradas mais importantes que as propriedades químicas, visto que após o acondicionamento do substrato nos recipientes, torna-se difícil alterá-las, já as características químicas podem ser mais facilmente ajustadas através da fertirrigação (KRATZ et al., 2013).

A densidade de um substrato é importante para auxiliar na interpretação de outras características, tais como porosidade, espaço de aeração e disponibilidade de água (FERMINO, 2014). Ademais, a densidade é uma importante propriedade para o manejo, além de influenciar nos custos de transporte, manipulação e infraestrutura necessária para sua utilização (FERNANDES et al., 2006).

Considera-se como referência para substratos utilizados em bandejas, valores de densidade volumétrica entre 100 e $300 \mathrm{~kg} \mathrm{~m}^{-3}$; para vasos de até $15 \mathrm{~cm}$ de altura, de 250 a 400 $\mathrm{kg} \mathrm{m}^{-3}$; para vasos de 20 a $30 \mathrm{~cm}$, de 300 a $500 \mathrm{~kg} \mathrm{~m}^{-3}$; para vasos maiores, de 500 a $800 \mathrm{~kg} \mathrm{~m}^{-3}$ (FERMINO, 2014). Desta maneira, os substratos T1, T2 e T3 (estercos de coelho sob diferentes processamentos) e $\mathrm{T} 4$ atendem a este referencial para uso em bandejas, sendo que apenas o substrato T3 apresentou densidade volumétrica um pouco acima do referencial proposto, possivelmente por conta da ausência de organismos processadores do material, quando comparado aos substratos T1 e T2, processados por minhocas e larvas, respectivamente.

Gonçalves; Poggiani (1996) também estabeleceram faixas adequadas para as características físicas dos substratos. Para a porosidade total os autores consideram como adequadas percentuais entre 75 a $85 \%$. Apenas o substrato T3 ficou dentro da faixa especificada e os demais apresentaram porosidade total um pouco abaixo, entre $71-74 \%$ (Tabela 2) A porosidade total, segundo Kämpf (2005), é de fundamental importância para o crescimento das plantas, visto que a alta 
concentração de raízes formadas nos recipientes exige elevado fornecimento de oxigênio e rápida remoção do gás carbônico formado.

Quanto à microporosidade, apenas o substrato T4 apresentou percentuais dentro da faixa adequada (45-55\%), segundo Gonçalves; Poggiani (1996). De forma contrária, os substratos T1 e T2 apresentaram microporosidade de 41,7 e $39,9 \%$, respectivamente, consideradas pelos autores como níveis médios (Tabela 2) e o substrato T3 apresentou microporosidade um pouco acima, considerada alta.

Gonçalves; Poggiani (1996) consideram a faixa de 35$45 \%$ como sendo os níveis adequados para a macroporosidade. No entanto, todos os substratos apresentaram macroporosidade variando de 22,4 a $31,3 \%$ (Tabela 2), considerados níveis médios pelos mesmos autores.

Destaca-se neste conjunto de resultados sobre as propriedades físicas dos substratos, que o processamento do esterco de coelho realizado tanto por meio de minhocas quanto por meio de larvas de Cetoniinae resultou em substratos com valores de densidade e de macroporosidade mais próximos aos recomendados pela literatura, quando comparados ao processamento realizado por compostagem.

4.2. Variação do $\mathrm{pH}$ e da condutividade elétrica dos substratos durante o desenvolvimento das mudas de alface

Kratz; Wendling (2013) relatam que tratando-se da utilização de substratos orgânicos, sem a adição de solo na composição, a recomendação é trabalhar em um intervalo de pH de 4,4 a 6,2. De acordo Kratz et al. (2014), os substratos que apresentam valores de $\mathrm{pH}$ abaixo de 5,0 podem ocasionar a deficiência de nitrogênio, potássio, cálcio, magnésio e boro, enquanto que em $\mathrm{pH}$ acima com valores acima de 6,5 são esperadas deficiências de fósforo, ferro, manganês, zinco e cobre.

Embora todos os substratos avaliados apresentassem valores de $\mathrm{pH}$ superiores (Figura 1) à faixa considerada ideal, os prejuízos observados no desenvolvimento e qualidade das mudas de alface para o substrato T3 - Esterco de coelho processado por compostagem natural não foram causados pelo $\mathrm{pH}$ elevado e sim pela elevada condutividade elétrica, a qual será discutida a seguir no item 4.3. Costa (2014) destaca que a alface é uma espécie adaptada a valores de $\mathrm{pH}$ alcalinos, tolerando $\mathrm{pH}$ de 6,5 a 7,5.

A redução da condutividade elétrica está diretamente relacionada com a extração de nutrientes realizada pelas mudas no decorrer de seu desenvolvimento nas bandejas. Antunes (2017) também verificou queda acentuada da condutividade elétrica no substrato SIPA após sete dias do cultivo de mudas de alface em bandejas. $\mathrm{O}$ autor ainda relata que a irrigação diária pode promover a eventual lixiviação de nutrientes, caso seja excessiva.

Os valores de condutividade elétrica registrados neste trabalho para os substratos T1 e T2 (esterco de coelho processado por minhocas e larvas de Cetoniinae, respectivamente) corroboram com os valores encontrados por Antunes (2017), o qual observou até os 21 dias a capacidade dos gongocompostos manterem os níveis de condutividade elétrica mais estáveis em relação ao substrato SIPA (T4), ou seja, foram capazes de reter e disponibilizar nutrientes às mudas de alface liberando-os gradualmente.

4.3. Desenvolvimento das mudas de alface em diferentes substratos
Os melhores desempenhos das mudas de alface foram proporcionados pelos substratos à base de esterco de coelho (T1 e T2), que por terem sido processados por organismos decompositores, apresentaram os maiores conteúdos de nutrientes totais e disponíveis - principalmente para o substrato T2, cujo o esterco foi processado por larvas de Cetoniinae (Tabela 1), quando comparados com o substrato de esterco de coelho sem organismos decompositores (T3) e SIPA (T4).

Neste sentido, a estabilização do esterco de coelho por meio da atividade da fauna saprófaga, de forma geral, promove o aumento da área superficial dos resíduos orgânicos, a qual é o requisito inicial mais importante durante a decomposição, estimulando as atividades microbianas e, por sua vez, a velocidade de biotransformação da matéria orgânica, (GERLACH et al., 2012; AMBARISH; SRIDHAR, 2013), além de enriquecer o solo com a adição de nutrientes e matéria orgânica, tornando-se uma prática sustentável, umas vez que, contribui na redução de resíduos, bem como favorece a redução de custos com aquisição de substratos comerciais.

Cabe destacar que os teores de $\mathrm{N}$ disponível dos substratos constituídos por esterco de coelho foram mais que o dobro do valor observado no substrato SIPA (T4). O melhor desempenho dos substratos constituídos por esterco de coelho processados por meio de vermicompostagem e de larvas de Cetoniinae também pode estar relacionado à maior capacidade destes substratos em repor os nutrientes extraídos ou lixiviados, o que é indicado pela menor redução da condutividade elétrica apresentada por estes substratos ao longo do desenvolvimento das mudas (Figura 2).

O desempenho inferior das mudas de alface produzidas no substrato de esterco de coelho sob compostagem natural (T3), provavelmente, foi devido à elevada condutividade elétrica apresentada por esse substrato no tempo zero de desenvolvimento das mudas $\left(2,32 \mathrm{mS} \mathrm{cm} \mathrm{cm}^{-1}\right)$, valor que ultrapassa a faixa de 1,0 a $2,0 \mathrm{mS} \mathrm{cm}^{-1}$, que é considerada a ideal para substratos (ARAÚJO NETO et al., 2009). Segundo Oliveira et al. (2011), a alface é uma espécie "moderadamente sensível" à salinidade, tendo a produção decrescida em 13\% por aumento unitário de condutividade elétrica do extrato de saturação (CEes) acima de $1,3 \mathrm{mS} \mathrm{cm} \mathrm{cm}^{-1}$. Andriolo et al. (2005) avaliaram o desenvolvimento da alface (cv 'Elba') cultivada em areia, onde aplicaram diferentes soluções nutritivas com condutividade elétrica variando de 0,80 a $4,72 \mathrm{mS} \mathrm{cm}^{-1}$ e constataram níveis que valores de condutividade elétrica acima de $2,0 \mathrm{mS} \mathrm{cm}^{-1}$ reduziram o crescimento e a massa fresca das plantas, corroborando com os dados encontrados neste trabalho para o substrato T3.

Antunes (2017) avaliou a eficiência do substrato orgânico gerado pela atividade decompositora de diplópodes da espécie Trigoniulis corallinus na produção de mudas de alface, registrando valores médios de massa fresca de parte aérea e raízes de 732 e $196 \mathrm{mg}$, respectivamente. Os dados obtidos neste trabalho superam os encontrados pelo autor, sendo que a massa fresca de parte aérea no substrato de esterco de coelho processado por lavas de Cetoniinae foi o dobro de peso, considerando que em ambos os trabalhos as mudas foram avaliadas aos 28 dias após a semeadura.

Para Oyedele et al. (2006) o processo de ingestão de solo e resíduos orgânicos pelas minhocas leva à formação de coprólitos, que são agregados biogênicos estáveis e resistentes a ciclos de umedecimento e secagem do solo. É possível que o mesmo tenha ocorrido com as fezes das larvas 
de Cetoniinae. Esta hipótese é reforçada pela maior macroporosidade (Tabela 2) dos substratos constituídos por esterco de coelho processado por meio de vermicompostagem e por meio de larvas de Cetoniinae, quando comparados aos demais substratos.

A estabilidade do torrão é uma característica importante, pois tem impacto direto na taxa de sobrevivência das mudas após o seu transplante. Antunes et al. (2018) buscaram avaliar o desempenho agronômico de mudas de alface produzidas em gongocompostos e comprovaram que a qualidade da muda transplantada a campo foi capaz de influenciar no desempenho produtivo da cultura da alface, atribuindo a estabilidade do torrão como uma das caraterísticas decisivas no estabelecimento da muda nos canteiros de produção. Os autores registraram notas médias 3, as quais foram semelhantes as registradas para os substratos T1 e T2 (Tabela 3), processado por minhocas e larvas de Cetoniinae, respectivamente.

\section{CONCLUSÕES}

O esterco de coelho apresenta características químicas e físicas favoráveis à sua utilização como substrato na produção de mudas de alface, sendo recomendável que o seu processamento seja realizado por meio de vermicompostagem com Eisenia fetida ou por meio de larvas de Cetoniinae.

\section{REFERÊNCIAS}

AMBARISH, C. N.; SRIDHAR, K. R. Production and quality of pill-millipede manure: a microcosmo study. Agricultural Research, v. 2, n. 3, p. 258-264, 2013. DOI: https://dx.doi.org/10.1007/s40003-013-0075-5

ANDRIOLO, J. L.; LUZ, G. L.; WITTER, M. H.; GODOI, R. S.; BARROS, G. T.; BORTOLOTTO, O. C. Growth and yield of lettuce plants under salinity. Horticultura Brasileira, Brasília, v. 23, n. 4, p. 931-934, 2005. DOI: http://dx.doi.org/10.1590/S0102-05362005000400014

ANTUNES, L. F. D. S.; SIVA, D. G. da; CORREIA, M. E. F.; LEAL, M. A. D. A. Avaliação química de substratos orgânicos armazenados e sua eficiência na produção de mudas de alface. Revista Científica Rural, Bagé, v. 21, n. 2, p. 139-155, 2 ago. 2019. DOI: https://dx.doi.org/10.30945/rcr-v21i2.2680

ANTUNES, L. F. S.; SCORIZA, R. N.; FRANÇA, E. M.; SILVA, D. G.; CORREIA, M. E. F.; LEAL, M. A. DE A.; ROUWS, J. R. C. Desempenho agronômico da alface crespa a partir de mudas produzidas com gongocomposto. Revista Brasileira de Agropecuária Sustentável (RBAS), Viçosa, v. 8, n. 3, p. 57-65, 2018. DOI: http://dx.doi.org/10.21206/rbas.v8i3.3009

ANTUNES, L. F S. Produção de gongocompostos e sua utilização como substrato para mudas de alface. 2017. 73f. Dissertação (Mestrado em Agronomia Ciência do Solo) - Universidade Federal Rural do Rio de Janeiro, Seropédica, 2017.

AQUINO, A. M. Integrando compostagem e vermicompostagem na reciclagem de resíduos orgânicos domésticos. Seropédica: Embrapa Agrobiologia, 2005. 4 p. (Embrapa - CNPAB. Circular técnica, 12).

ARAÚJO NETO, S. E.; AZEVEDO, J. M. A.; GALVÃO, R. O.; OLIVEIRA, E. B. L.; FERREIRA, R. L. F. Produção de muda orgânica de pimentão com diferentes substratos. Ciência Rural, Santa Maria, v. 39, n. 5, 2009.

DOI:

http://dx.doi.org/10.1590/S0103-

84782009005000099

BERNAL, M. P.; ALBURQUERQUE, J. A.; MORAL, R. Composting of animal manures and chemical criteria for compost maturity assessment. A review. Bioresource Technology, Essex, v. 100, n. 22, p. 5444-5453, 2009. DOI:

https://dx.doi.org/10.1016/j.biortech.2008.11.027

BERTI, C. L. F.; KAMADA, T.; SILVA, M. P.; MENEZES, J. F. S.; OLIVEIRA, A. C. S. Crescimento de mudas de baru em substrato enriquecido com nitrogênio, fósforo e potássio. Cultura Agronômica: Revista de Ciências Agronômicas, Ilha Solteira, v. 26, n. 2, p. 191-202, 2017. BRASIL. MINISTÉRIO DA AGRICULTURA, PECUÁRIA E ABASTECIMENTO (MAPA). Instrução Normativa SDA No 17. Métodos Analíticos Oficiais para Análise de Substratos para Plantas e Condicionadores de Solo. Diário Oficial da União, 2007.

BRUM JÚNIOR. S. B.; PELLEGRINI, L. G.; SILVA, E. S.; SILVA, M. C. B.; LIMA, Q. T.; PELLEGRIN, A. C. R. S. Implantação da cunicultura como uma alternativa de produção de proteína animal para a comunidade carente de São João do Barro preto - Brasil. Revista Brasileira de Cunicultura, v. 2, n. 1, p. 01 - 16, 2012.

COSTA, A. R. Nutrição Mineral de Plantas Vasculares. Escola de Ciências e Tecnologia da Universidade de Évora, Portugal. 2014. 147 p.

FERMINO, M. H. Substratos: composição, caracterização e métodos de análise. Guaíba: Agrolivros, 2014. 112 p.

FERNANDES, C.; CORÁ, J. E.; BRAZ, L. T. Desempenho de substratos no cultivo do tomateiro do grupo cereja. Horticultura Brasileira, Vitória da Conquista, v. 24, p. 42-46, 2006. DOI: http://dx.doi.org/10.1590/S010205362006000100009

FERREIRA, D. C. Sisvar: a Guide for its Bootstrap procedures in multiple comparisons. Ciência e agrotecnologia, v. 38, n. 2, p. 109-112, 2014. DOI: http:/ /dx.doi.org/10.1590/S1413-70542014000200001

GARRONE, R. F.; DE CAMPOS, A. G.; SILVEIRA, C. P.; JUNIOR, J. L. Produção de biomassa, diagnose nutricional e absorção de nitrogênio e cálcio durante crescimento inicial do pinhão-manso. Revista Ciência Agronômica, Fortaleza, v. 47, n. 1, p. 22-31, 2016. DOI: http://dx.doi.org/10.5935/1806-6690.20160003

GERLACH, A.; RUSSELL, D. J.; ROMBKE, J.; BRUGGEMANN, W. Consumption of introduced oak litter by native decomposers (Glomeridae, Diplopoda). Soil Biology \& Biochemistry, Elmsford, v. 44, n. 1, p. 26- 30, $2012 . \quad$ DOI: https://dx.doi.org/10.1016/j.soilbio.2011.09.006

GÓMEZ-BRANDÓN, M.; LORES, M.; DOMÍNGUEZ, J. Changes in chemical and microbiological properties of rabbit manure. Bioresource Technology, Essex, v. 128, p. 310-316, 2013. DOI: https://dx.doi.org/10.1016/j.biortech.2012.10.112

GONÇALVES, J. L. M.; POGGIANI, F. Substratos para produção de mudas florestais. In: Congresso Latino Americano de Ciência do Solo, 13., 1996, Águas de Lindóia. Anais... Águas de Lindóia: USP ESALQ/SBCS/CEA/SLACS/SBM, 1996. CD Rom. 
IBGE_INSTITUTO BRASILEIRO DE GEOGRAFIA E ESTATÍSTICA. Censo Agropecuário de 2017. Disponível https://sidra.ibge.gov.br/Tabela/6619\#resultado. Acesso em: 28 set. 2019.

INMET_INSTITUTO NACIONAL DE METEOROLOGIA. Gráficos Climatológicos (19311960 e 1961-1990). Disponível em:http://www.inmet.gov.br/portal/index.php?r=clima /graficosClimaticos. Acesso em: 09 out. 2019.

KÄMPF, A.N. Produção comercial de plantas ornamentais. Guaíba: Agropecuária, 2005. 256 p.

KRATZ, D.; NOGUEIRA, A. C.; WENDLING, I.; SOUZA, P. V. D. Substratos renováveis para produção de mudas de Mimosa scabrella. Floresta, Curitiba, v. 45, n. 2, p. 393-408, 2014. DOI: http://dx.doi.org/10.5380/rf.v45i2.31249

KRATZ， D.; WENDLING， I.; NOGUEIRA， A. C.; SOUZA, P. V. D. D. Propriedades físicas e químicas de substratos renováveis. Revista Árvore, Viçosa, v. 37, n. 6, p. 1103-1113, 2013. DOI: http://dx.doi.org/10.1590/S0100-67622013000600012

KRATZ, D.; WENDLING, I. Produção de mudas de Eucalyptus dunnii em substratos renováveis. Floresta, Curitiba, v. 43, n. 1, p. 125-136, 2013. DOI: http://dx.doi.org/10.5380/rf.v43i1.25989

LIAO, C. F. H. Devarda's Alloy Method for Total Nitrogen Determination. Soil Science Society of America Journal, v. 45, n. 5, 1981.

MORAL, R.; MORENO-CASELLES, J.; PEREZMURCIA, M.D.; PEREZ-ESPINOSA, A.; RUFETE, B.; PAREDES, C. Characterisation of the organic matter pool in manures. Bioresource Technology, Essex, v. 96, n. 2, p. 153 - 158, 2005. DOI: https://dx.doi.org/10.1016/j.biortech.2004.05.003

OLIVEIRA, E. A. G.; LEAL, M. A. A.; ROCHA, M. S.; GUERRA, J. G. M.; RIBEIRO, R. L. D. Avaliação da estabilidade de materiais orgânicos por meio de incubação e da captura conjunta das emissões de $\mathbf{C O}_{2}$ e de $\mathbf{N H}_{3}$. Seropédica: Embrapa Agrobiologia, 2014. 32 p. (Embrapa Agrobiologia. Boletim de Pesquisa e Desenvolvimento, 97).
OLIVEIRA, F. A.; CARRILHO, M. J. S. O.; MEDEIROS, J. F.; MARACAJÁ, P. B.; OLIVEIRA, M. K. T. Desempenho de cultivares de alface submetidas a diferentes níveis de salinidade da água de irrigação. Revista Brasileira de Engenharia Agrícola e Ambiental, Campina Grande, v. 15, n. 8, p. 771-777, 2011. DOI: http://dx.doi.org/10.1590/S141543662011000800002

OYEDELE, D.J.; SCHJONNING, P.; AMUSAN, A.A. Physicochemical properties of earthworm casts and undingested parent soil from selected sites in southwestern Nigeria. Ecological Engineering, Oxford, v. 28, n. 2, p. 106-113, 2006. DOI: https://dx.doi.org/10.1016/j.ecoleng.2006.05.002

PEREIRA, C.M.S. Efeito das larvas de besouro no processo de decomposição de esterco de coelho e produção de substratos orgânicos para mudas de hortaliças. 2017. 65f. Tese (Doutorado) Universidade Federal Rural do Rio de Janeiro, Seropédica. 2017.

QUEIROZ, C. R. A. A.; ANDRADE R. R.; LACERDA Z. C.; FERREIRA M. E. Esterco de coelho: fonte de nutrientes para complementação da adubação. Revista Agrogeoambiental, v. 6, n. 3, p. 11-17, 2014. DOI: http://dx.doi.org/10.18406/2316-1817v6n32014680

SILVA, L. G. F.; DE BARROS, B.; SANTOS, J. V. G.; MANZOLI, V. Q.; DE SALLES, R. A.; DE OLIVEIRA, F. A.; SILVA BERILLI, S. Efeito da adubação foliar com diferentes fontes de magnésio no desenvolvimento de mudas do mamão. SEAGRO: Anais da Semana Acadêmica do Curso de Agronomia DO CCAE/UFES, v. 1, n. 1, 2017.

TEIXEIRA, P.C.; DONAGEMA, G.K.; FONTANA, A.; TEIXEIRA, W.G. Manual de métodos de análise do solo. 3. ed. Brasília: Embrapa, 2017, 573 p.

VIEIRA, C. R.; WEBER, O. L. S; SCARAMUZZA, J. F. Saturação por bases e doses de $\mathrm{P}$ no crescimento e nutrição de mudas de cerejeira (Amburana Acreana Ducke). Nativa, Sinop, v. 3, n. 1, p.01-09, 2015.

YONG, J. W. H.; NG, Y. F.; TAN, S. N.; CHEW, A. Y. L. Effect of fertilizer application on photosynthesis and oil yield of Jatropha curcas L. Photosynthetica, Prague, v. 48, p. 208-218, 2010. DOI: https://dx.doi.org/10.1007/s11099-010-0026-3 